\title{
Bioestimulação micorrízica com óleo essencial em mudas de Enterolobium contorsiliquum e Bauhinia forficata em solo contaminado com cobre
}

\author{
Mycorrhizal bioestimulation with essential oil on \\ Enterolobium contorsiliquum and Bauhinia forficata seedlings in \\ soil contaminated with copper
}

\author{
Rodrigo Ferreira da Silva ${ }^{1 *}$; Clovis Orlando Da Rosi ${ }^{1}$; Alex Dellai²; \\ Douglas Leandro Scheid ${ }^{3}$; André Luiz Grolli ${ }^{3}$; Hazael Soranzo de Almeida ${ }^{4}$
}

\section{Resumo}

\begin{abstract}
O uso de espécies arbóreas nativas inoculadas com fungo ectomicorrízico pode ser uma alternativa para revegetação de solo contaminado com cobre. O objetivo do trabalho foi avaliar a interferência do óleo essencial de eucalipto, cobre e ectomicorriza na qualidade de mudas de timbaúva-preta (Enterolobium contorsiliquum) e pata-de-vaca (Bauhinia forficata). O trabalho foi conduzido em casa de vegetação por 120 dias, usando como substrato a camada de $0-20 \mathrm{~cm}$ de um Latossolo Vermelho com textura argilosa. $\mathrm{O}$ delineamento experimental foi inteiramente casualizado em arranjo fatorial $(2 \times 2 \times 2)$, sendo "com e sem" inoculante ectomicorrízico, óleo essencial e adição de $150 \mathrm{mg} \mathrm{kg}^{-1}$ de cobre no solo. Avaliouse a altura da planta, diâmetro de colo, massa seca da parte aérea, das raízes e total, comprimento e área superficial específica radicular e a qualidade das mudas pelas relações entre: altura da parte aérea e diâmetro do colo, altura da parte aérea e massa seca da parte aérea e pelo índice de qualidade de Dickson. A formação da ectomicorriza foi identificada pela visualização de estruturas fúngicas na morfologia externa e interna do sistema radicular. A adição de cobre reduziu o diâmetro do colo e massa seca da parte aérea das mudas de pata-de-vaca independente da adição de inoculante e óleo. Não houve formação de ectomicorriza, mesmo quando aplicado óleo essencial nas mudas da timbaúva-preta e patade-vaca. O crescimento das mudas da timbaúva-preta é estimulado pela adição de $150 \mathrm{mg} \mathrm{kg}^{-1}$ de cobre e apresenta maior índice de qualidade de mudas em relação a pata-de-vaca.
\end{abstract}

Palavras-chave: Qualidade de mudas, arbórea nativa, metal pesado

\begin{abstract}
The use of native tree species inoculated with ectomycorrhizal fungus can be an alternative for revegetation of soil contaminated with copper. The objective was to evaluate the interference of eucalyptus essential oil copper and ectomycorrhiza on growth and quality of seedlings timbaúva-preta (Enterolobium contorsiliquum) and pata-de-vaca (Bauhinia forficata). The study was conducted in
\end{abstract}

\footnotetext{
${ }^{1}$ Eng $^{{ }^{s}}$ Agr $^{\text {os }}$, Profs. Drs., Dept ${ }^{\circ}$ de Ciências Agronômicas e Ambientais, Universidade Federal de Santa Maria, UFSM, Frederico Westphalen, RS. E-mail: rodrigosilva@smail.ufsm.br; clovisdaros@gmail.com

${ }^{2}$ Eng $^{\circ}$ Agr $^{\circ}$ M.e em Agronomia: Agricultura e Ambiente, PPGAAA, UFSM, Frederico Westphalen, RS. E-mail: adellai2@yahoo. com.br

${ }^{3} \mathrm{Eng}^{\mathrm{o}_{\mathrm{s}}} \mathrm{Agr}^{\mathrm{os}_{\mathrm{s}}}$, Discentes do Curso de Mestrado do Programa de Pós-Graduação em Agronomia: Agricultura e Ambiente, PPGAAA, UFSM, Frederico Westphalen, RS. Bolsista CAPES. E-mail: douglasscheid@gmail.com; andregrolli1990@hotmail.com

${ }^{4}$ Eng $^{\circ}$ Agr $^{\circ}$, Discente do Curso de Mestrado do Programa de Pós-Graduação em Agrobiologia, UFSM, Santa Maria, RS. Bolsista CAPES. E-mail: hazaelsoranzo@yahoo.com.br

* Autor para correspondência
} 
greenhouse for 120 days using as substrate the layer of $0-20 \mathrm{~cm}$ of a Red Oxisol with very clayey texture. The experimental design was completely randomized factorial $(2 \times 2 \times 2)$, and " with and without " inoculant ectomycorrhizal essential oil and addition of $150 \mathrm{mg} \mathrm{kg}^{-1}$ of copper in the soil . Was evaluated the plant height, stem diameter, dry mass of shoots, roots and total length and specific surface area and root seedling quality of relations between: shoot height and stem diameter, shoot height and dry mass of shoots and the quality index of Dickson. The formation of ectomycorrhiza was identified by visualization of fungal structures and surface morphology internal and external morphology of the root system. Addition of copper reduced de stems diameter and dry mass of de aerial part of the pata-de-vaca seedlings regardless of the addition of inoculant and oil. There was no formation of ectomycorrhiza, even when applied in the essential oil of seedlings timbaúva-preta and pata-de-vaca. Growth of timbaúvapreta seedlings is stimulated by the addition of $150 \mathrm{mg} \mathrm{kg}^{-1}$ of copper and has a higher rate of seedling quality in relation to pata-de-vaca.

Key words: Seedlings quality, native tree, heavy metal

\section{Introdução}

A contaminação do ambiente com cobre é resultado do crescimento da atividade mineradora e industrial, do descarte inadequado dos resíduos sólidos e líquidos e da utilização excessiva de fungicidas cúpricos (NACHTIGALL et al., 2007 e ANDRADE et al., 2009) e que causam impactos que afetam a sociedade, a fauna e a flora (CAMARGO et al., 2007).

Uma alternativa para descontaminação de áreas contaminadascommetaiséouso de espécies vegetais, através da técnica conhecida como fitorremediação. Esta técnica visa reduzir a quantidade de metais presente no solo por meio da extração realizada pela planta, com acúmulo dos metais em seus tecidos (ACCIOLY; SIQUEIRA, 2000), sendo aplicável in situ (MARQUES; AGUIAR; SILVA, 2011). Silva et al. (2011a) estudando espécies nativas em solo arenoso contaminado concluíram que as mudas de aroeira-vermelha (Schinus therebinthifolius Raddi) são mais tolerante ao cobre do que o açoita-cavalo (Luehea divaricata Mart. \& Zucc.). Isso indica a possibilidade de mecanismos distintos de tolerância ao cobre entre espécies arbóreas nativas do Brasil.

Outra possibilidade para aumentar a fitorremediação, ou a tolerância a metais no solo é a associação simbiótica de fungos ectomicorrízicos com plantas arbóreas. Esta associação possibilita às plantas maior absorção de nutrientes e água (SMITH; READ, 2008), pois Souza et al. (2012) encontraram maior absorção de fósforo em mudas de eucalipto, quando inoculadas com Pisolhitus microcarpus e Scleroderma flavidum, e os fungos podem ainda produzir moléculas quelantes de metais ou imobilizá-los em suas hifas, impedindo que sejam absorvidos pelas raízes dos vegetais (OLIVEIRA; OLIVEIRA; ROSSI, 2010). Por isso, mudas de canafístula (Peltophorum dubium) reduzem a absorção de cobre, quando associadas a fungos ectomicorrízicos (SILVA et al., 2010), com eficiência micorrízica de até $46 \%$ (SILVA et al., 2011b). Desse modo, a revegetação com espécies arbóreas inoculadas com fungos ectomicorrízicos é uma estratégia interessante para recuperação de áreas contaminadas (OLIVEIRA; OLIVEIRA; ROSSI, 2010).

O uso de metabólitos secundários de plantas bioativas, conhecidos como óleos essenciais, também podem estimular o desenvolvimento de micorrizas (AKIYAMA; MATSUZAKI; HAYASHI, 2005) ou ativar mecanismos de defesa contra patógenos (BONALDO et al., 2007). Estudos têm demostrado que os fungos ectomicorrízicos são beneficiados pela presença de óleo essencial de Eucalyptus grandis quando submetidos a metais pesados (STEFFEN et al., 2011), a aplicação do óleo é bioestimulante do crescimento vegetativo de mudas de eucalipto (STEFFEN; ANTONIOLLI; STEFFEN, 2010) e o óleo contribui para a formação de ectomicorriza em mudas de sibipiruna (Caesalpinia peltophoroides Benth.) (STEFFEN 
et al., 2012). Nas espécies arbóreas nativas como a timbaúva-preta (Enterolobium contortisiliquum Vell.) e de pata-de-vaca (Bauhinia forficata Link) não existem trabalhos com associação micorrízica e óleo. O estudo destas espécies é importante, pois apresentam rápido crescimento inicial e são recomendadas para a recuperação de áreas degradadas (LORENZI, 2008).

Neste contexto, objetivou-se avaliar a qualidade de mudas de timbaúva-preta (Enterolobium contorsiliquum (Vell.) Morong) e pata-de-vaca (Bauhinia forficata Link) pela bioestimulação micorrízica com o uso do óleo essencial de eucalipto em solo contaminado com cobre.

\section{Material e Métodos}

O trabalho foi conduzido em casa de vegetação, pertencente ao Departamento de Ciências Agronômicas e Ambientais da UFSM, campus de Frederico Westphalen, Rio Grande do Sul, Brasil. Desenvolveram-se dois experimentos distintos, um para cada espécie florestal, pois, foram instalados com diferença de 20 dias. O delineamento experimental foi inteiramente casualizado, com seis repetições em arranjo fatorial $(2 \times 2 \times 2)$, sendo com e sem: inoculante (fungo ectomicorrízico), óleo essencial de eucalipto e adição de cobre no solo.

As unidades experimentais foram tubetes plásticos com capacidade de $125 \mathrm{~cm}^{-3}$, desinfetados com hipoclorito de sódio $1 \%(\mathrm{v} / \mathrm{v})$. O substrato utilizado foi solo classificado como Latossolo Vermelho (EMBRAPA, 2006), com os seguintes atributos: $\mathrm{pH}_{\text {água }}$ : 5,0; $\mathrm{Ca}+\mathrm{Mg}: 4,8 \mathrm{Cmol}_{\mathrm{c}} \mathrm{dm}^{-3}$, $\mathrm{H}+\mathrm{Al}: 3,1 \mathrm{Cmol}_{\mathrm{c}} \mathrm{dm}^{-3}$, P: $8,7 \mathrm{mg} \mathrm{dm}^{-3}, \mathrm{~K}: 20 \mathrm{Cmol}_{\mathrm{c}}$ $\mathrm{dm}^{-3}, \mathrm{Cu}: 0,8 \mathrm{mg} \mathrm{dm}^{-3}$, matéria orgânica: 7,0 $\mathrm{g}$ $\mathrm{dm}^{-3}$ e argila: $790 \mathrm{~g} \mathrm{dm}^{-3}$. Antes do preenchimento dos tubetes foi adicionado calcário ao solo para correção da acidez a pH 5,5. O solo foi esterilizado por três vezes, durante 30 minutos, com intervalo de 24 horas, em autoclave à temperatura de $121^{\circ} \mathrm{C}$. Posteriormente adicionou-se $150 \mathrm{mg} \mathrm{kg}^{-1}$ de cobre, na forma de sulfato de cobre nos tratamentos com adição de cobre.

As espécies arbóreas nativas testadas foram timbaúva-preta (Enterolobium contortisiliquum (Vell.) Morong) e pata-de-vaca (Bauhinia forficata Link). As sementes das espécies florestais foram desinfectadas com imersão em hipoclorito de sódio (1\%) e em etanol (70\%) por 30 segundos e escarificadas mecanicamente para a quebra da dormência. Foram usadas três sementes por recipiente plástico e quando as plântulas apresentavam um par de folhas definitivas efetuouse o desbaste, deixando uma plântula por recipiente. As mudas foram cultivadas por 120 dias com irrigação diária e fertilizadas com solução nutritiva de HOAGLAND, suprimida de cobre, a cada 30 dias. As sementes das espécies foram provenientes do Centro de Pesquisas da Fundação Estadual de Pesquisa Agropecuária (FEPAGRO - Santa Maria $-\mathrm{RS})$.

$\mathrm{Na}$ semeadura das espécies foram aplicados inoculante e óleo essencial. O óleo essencial foi obtido através da técnica de hidrodestilação de folhas in natura de eucalipto (VITTI; BRITO, 2003). Porções de aproximadamente $2 \mathrm{~cm}$ de folhas de Eucalyptus grandis, separadas em lotes de 100 g, foram colocadas para ebulição no aparelho de Clevenger modificado (SERAFINI; CASSEL, 2001), composto por um balão de fundo redondo com aquecimento externo. Os exsudatos vegetais condensados foram coletados e mantidos sob refrigeração a $4^{\circ} \mathrm{C}$. No momento da aplicação o óleo essencial foi solubilizado em etanol $96 \%$ na proporção de 1:1 (v/v) (FABROWSKI et al., $2003)$ e, soluções com concentração de $40 \mu \mathrm{L} \mathrm{L}^{-1}$ (STEFFEN; ANTONIOLLI; STEFFEN, 2010), foram aplicadas sobre o solo nas doses de $5 \mathrm{~mL}$ por tubete, aos 7, 14 e 21 dias após o surgimento do primeiro par de folhas definitivas.

Ainoculação do solo com fungos ectomicorrízicos partiu do preparo de uma suspensão miceliana a partir do meio de cultura sólido Melin-Norkrans 
modificado (MARX, 1969) contendo (Pisolithus microcarpus) (UFSC-Pt116) cultivado em $\mathrm{pH} \mathrm{5,8}$ e temperatura de $28^{\circ} \mathrm{C}$. Em liquidificador, discos de $10 \mathrm{~mm}$ de diâmetro da cultura sólida foram fragmentados com $50 \mathrm{~mL}$ de água destilada, por 10 segundos, e então, aplicou-se $4 \mathrm{~mL}$ da suspensão por tubete, repetindo-se por três vezes com intervalo de 30 dias.

Foram avaliados os seguintes parâmetros: a) altura da planta (AP), medida com régua graduada do colo da planta até o meristema apical; b) diâmetro de colo (DC), medido com paquímetro digital; c) massa seca da parte aérea (MSA); d) massa seca radicular (MSR), e) massa seca total (MST), obtida pela soma da MSA e MSR; f) comprimento radicular (CR) e g) área superficial específica (ASE) conforme metodologia de Tennant (1975). A matéria seca foi quantificada após secção da parte aérea e radicular na região do colo da planta e secadas em estufa, a temperatura de $65^{\circ} \mathrm{C}$, até massa constante.

Com base nos parâmetros morfológicos avaliados foram calculados os índices de qualidade de mudas: a) relação entre altura da parte aérea e diâmetro do coleto (AP/DC); b) relação entre a altura da parte aérea e massa seca da parte aérea (AP/MSA) e o índice de qualidade de Dickson (IQD), por meio da fórmula (DICKSON; LEAF; HOSNER, 1960): IQD $=\operatorname{MST}(\mathrm{g}) /[\mathrm{AP}(\mathrm{cm}) / \mathrm{DC}(\mathrm{mm})]+[\operatorname{MSA}(\mathrm{g}) / \mathrm{MSR}(\mathrm{g})]$.

Os resultados foram submetidos à análise de variância pelo teste $\mathrm{F}$ e quando significativos para interação, as médias foram submetidas ao teste de Tukey ao nível de significância de 95\% ( $\mathrm{p} \leq 0,05)$, pelo programa estatístico Sisvar (FERREIRA, 2011).

A formação de micorriza foi avaliada pela identificação visual das alterações na morfologia externa do sistema radicular e pela observação em microscópio óptico da morfologia interna (manto fúngico e rede de Hartig), mediante cortes histológicos transversais das raízes e, do cálculo do percentual de colonização radicular, conforme Brundrett et al. (1996).

\section{Resultados e Discussão}

A maior parte dos parâmetros avaliados não apresentou interação significativa entre inoculante, óleo e cobre (Tabela 1). O comprimento radicular das mudas de pata-de-vaca foi o único parâmetro que apresentou interação tripla significativa, na qual no tratamento sem cobre, a adição de óleo, ou de inoculante proporcionou maior comprimento radicular, porém, com adição de cobre, não foi evidenciado efeito do inoculante e do óleo essencial (Tabela 2). O efeito bioestimulante do óleo essencial também foi evidenciado no crescimento vegetativo de mudas de eucalipto (STEFFEN; ANTONIOLLI; STEFFEN, 2010), enquanto a inoculação com o fungo Pisolithus microcarpus, isolado UFSCPt116, propiciou maior massa seca da parte aérea de mudas de eucalipto (SOUZA et al., 2012). Esse resultado pode estar indicando a possibilidade do uso do óleo, ou do inoculante para promover o aumentar no comprimento radicular das mudas de pata-de-vaca em solo com baixa disponibilidade de cobre, contudo, ao se adicionar $150 \mathrm{mg} \mathrm{kg}^{-1}$ de cobre ao solo, não haveria a necessidade da aplicação do óleo, ou do inoculante ectomicorrízico.

Desdobrando as interações duplas, não foi evidenciado efeito significativo entre inoculante e óleo para os parâmetros avaliados, nas duas espécies estudadas (Tabela 1). Estes resultados diferem com os de Steffen et al. (2012) que encontraram efeito sinérgico entre inoculante e óleo essencial de eucalipto em mudas de sibipiruna, repercutindo em maior altura, diâmetro de colo e massa seca da parte aérea. Isso indica que as arbóreas nativas do Brasil respondem de forma diferente à associação da inoculação de fungos ectomicorrízicos e adição de óleo essencial, necessitando de estudos específicos para elucidar o comportamento individual de cada espécie. 
Tabela 1. Probabilidade do teste F para as interações e fatores principais da altura da parte aérea (AP), diâmetro de colo (DC), massa seca parte aérea (MSA), massa seca radicular (MSR), comprimento radicular (CR), área superficial específica das raízes (ASE), relação entre altura e diâmetro de colo (AP/DC), relação entre altura e massa seca parte aérea (AP/MSA) e índice de qualidade de Dickson (IQD) das mudas de timbaúva-preta e pata-de-vaca.

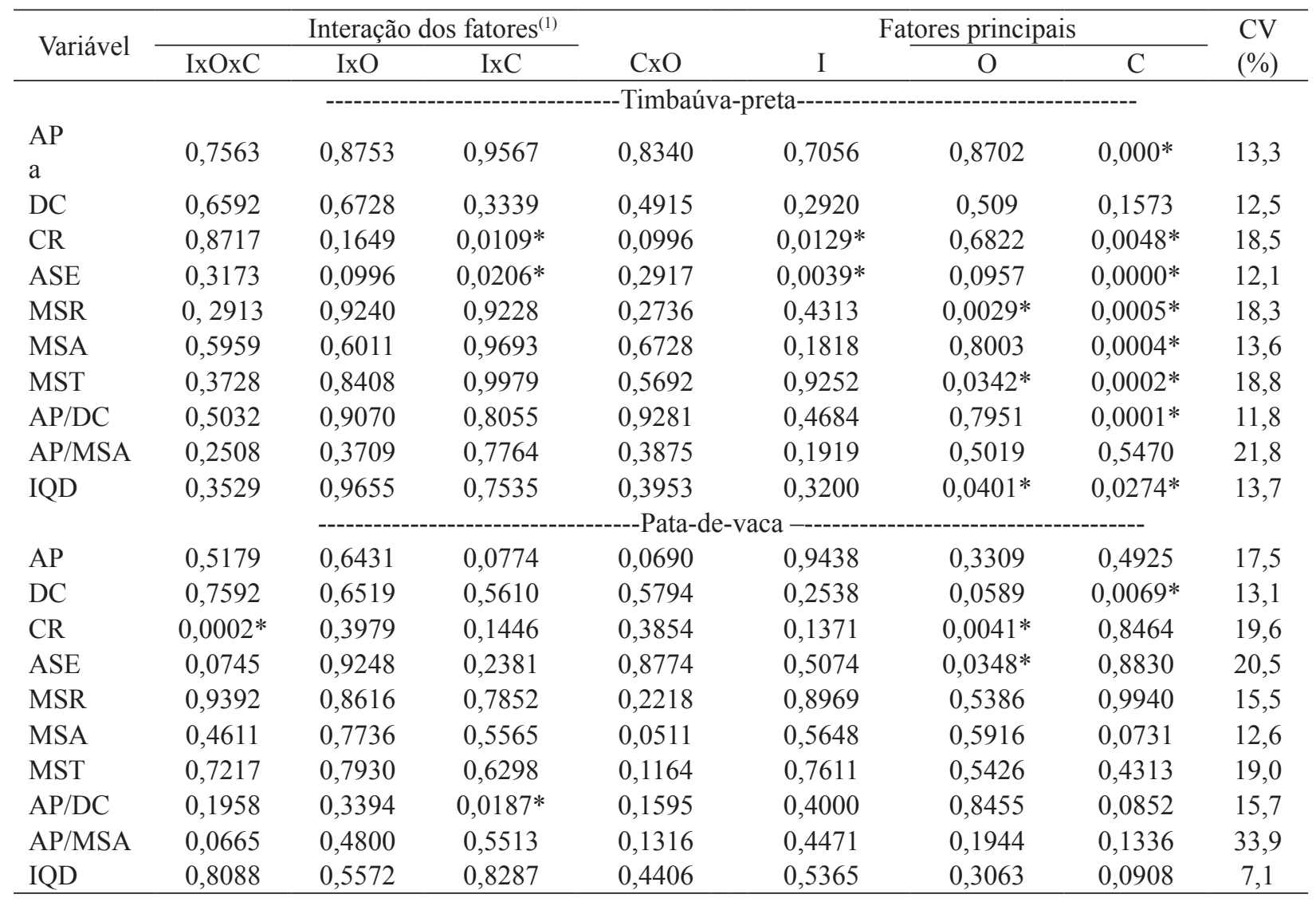

(1) I: Inoculante (Pt-116); O: Óleo essencial; C:Cobre. *Teste F significativo a 5\% de probabilidade de erro.

Fonte: Elaboração dos autores.

Tabela 2. Comparação dos efeitos de interação tripla do comprimento radicular das mudas de pata-de-vaca com e sem adição de inoculante, óleo essencial e cobre.

\begin{tabular}{|c|c|c|c|c|}
\hline \multirow{4}{*}{ Tratamentos } & \multicolumn{4}{|c|}{ Cobre } \\
\hline & \multicolumn{2}{|c|}{ Sem } & \multicolumn{2}{|c|}{ Com } \\
\hline & \multicolumn{2}{|c|}{ Inoculante } & \multicolumn{2}{|c|}{ Inoculante } \\
\hline & Sem & Com & Sem & Com \\
\hline Sem óleo & 39,62 Bba & 47,03 Aaa & 54,21 Aaa & 39,62 Aaa \\
\hline Com óleo & 51,07 Aaa & $23,34 \mathrm{Bbb}$ & $28,17 \mathrm{Bab}$ & 36,59 Aaa \\
\hline
\end{tabular}

(1) Médias seguidas da mesma letra, maiúscula para desdobramento de cobre, minúscula (negrito) desdobramento de óleo e minúscula desdobramento de inoculante, não diferem entre si para o teste de Tukey a $5 \%$ de probabilidade de erro.

Fonte: Elaboração dos autores. 
Observa-se interação significativa entre pode estar relacionada a formação de melaninas, inoculante e cobre, com aumento no comprimento radicular e área superficial específica radicular quando se inoculou ou adicionou-se cobre ao solo nas mudas de timbaúva-preta e, redução na relação altura/diâmetro do caule das mudas de patade-vaca com a inoculação sem adição de cobre (Tabela 3). Resultados das pesquisas indicam que fungos ectomicorrízicos apresentam tolerância a solos contaminados com metais (BERTOLAZI et al., 2010). Conforme Gadd (1993), essa tolerância que possuem muitos sítios de adsorção e ligação de íons metálicos. Desse modo, é possível que o crescimento radicular proporcionado pela inoculação tenha possibilitado maior exploração do solo, ou a imobilização de metais pelos fungos ectomicorrízicos reduzindo o efeito tóxico do cobre, ou adição deste elemento não tenha atingido concentrações tóxicas no solo, que varia de 40 $\mathrm{mg} \mathrm{kg}{ }^{-1}$ para solo arenoso e $100 \mathrm{mg} \mathrm{kg}^{-1}$ para solo argiloso (ACCIOLY; SIQUEIRA, 2000).

Tabela 3. Comprimento radicular (CR) e área superficial específica das raízes (ASE) de mudas de timbaúva-preta para a interação entre inoculante e cobre e relação da altura de plantas/diâmetro de colo (AP/DC) para mudas de pata-devaca para interação entre óleo e cobre e entre inoculante e cobre.

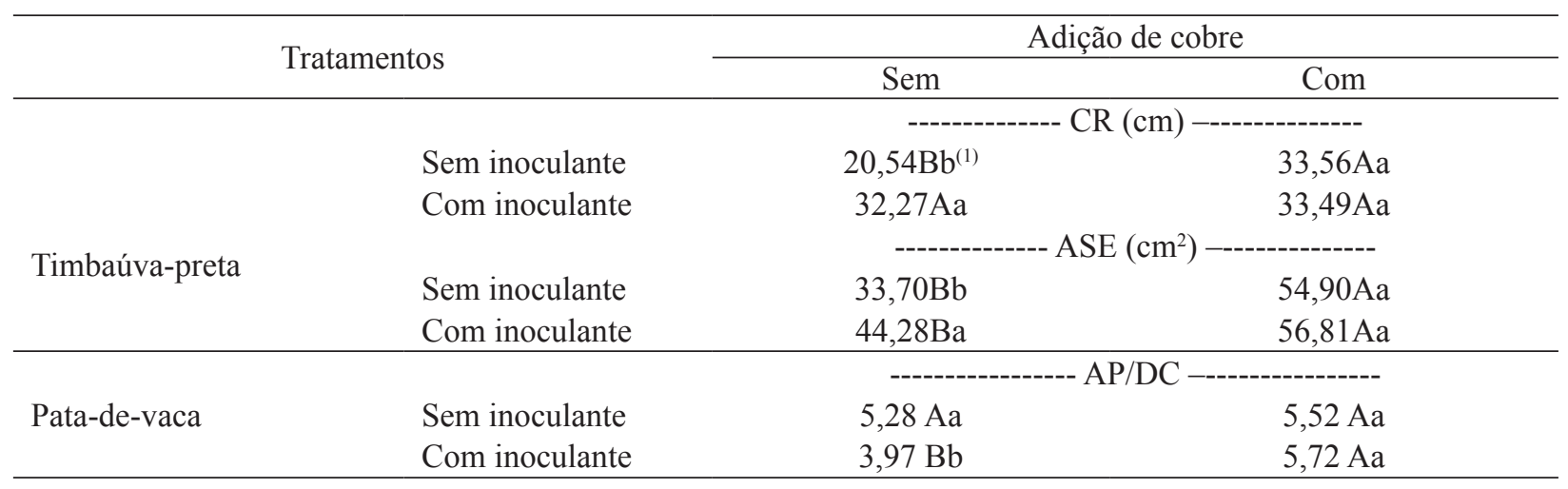

${ }^{(1)}$ Médias seguidas da mesma letra, maiúscula na linha e minúscula na coluna, não diferem entre si para o teste de Tukey a 5\% de probabilidade de erro.

Fonte: Elaboração dos autores.

$\mathrm{Na}$ análise dos efeitos simples, observa-se que a adição de óleo causou diminuição da massa seca radicular, total e no índice de qualidade de Dickson das mudas de timbaúva-preta e na área superficial específica radicular das mudas de pata-de-vaca (Tabela 4). Assim, o óleo além de não ter favorecido a micorrização pode ter causado efeito negativo sobre as plantas, pois apresenta potencial para atuar no manejo de plantas daninhas (BATISH et al., 2008), diminuindo a germinação e o crescimento das plantas (VERDEGUER; BLÁSQUEZ; BOIRA, 2009).

Segundo Duarte et al. (2012) óleo essencial de Eucalyptus camaldulensis e Eucalyptus grandis não tem efeito inibitório sobre plantas de Anadenanthera peregrina (Angico) em trabalho in vitro, porém podem apresentar este efeito em microrganismos do solo. Porém em mudas de Enterolobium contortisiliquum, o óleo extraído de E. camaldulensis afetou o crescimento, enquanto que o de $E$. grandis não apresentou efeito negativo (DUARTE et al., 2006). Resultados encontrados por Zhang e Fu (2009) demonstram que muitas espécies nativas sofrem algum efeito deletério na presença de óleo essencial de eucalipto, algumas espécies na germinação e outras durante seu desenvolvimento.

Não foi observado efeito simples significativo da inoculação do fungo ectomicorrízicos nos 
parâmetros avaliados para as duas espécies arbóreas utilizadas no trabalho (Tabela 1). Diagne et al. (2013) verificaram que a formação de ectomicorríza em Acacia mangium aumentou o crescimento da planta e a quantidade de nutrientes em seus tecidos, favorecendo o desenvolvimento das mudas. Silva et al. (2011b) obtiveram eficiência ectomicorrizica de $46 \%$ na massa seca da parte aérea de Canafístula
(Peltophorum dubium (Spreng.) Taub.) em Argissolo Vermelho Amarelo, com 19\% de argila, contaminado com cobre e com baixos teores de fósforo. Embora almejasse efeito positivo da inoculação, o isolado utilizado como inoculante parece não exercer efeito simples significativo para o crescimento de mudas de timbaúva-preta e patade-vaca.

Tabela 4. Comparação das médias apenas para os efeitos simples significativos da adição ou não do óleo essencial e de cobre na altura da parte aérea (AP), massa seca radicular (MSR), massa seca parte aérea (MAS), massa seca total (MST), relação entre altura e diâmetro de colo (AP/DC), relação entre altura e massa seca parte aérea (AP/MSA) e índice de qualidade de Dickson (IQD) nas mudas de timbaúva-preta e no diâmetro de colo (DC) e área superficial específica das raízes (ASE) nas mudas de pata-de-vaca.

\begin{tabular}{|c|c|c|c|c|}
\hline \multirow[b]{2}{*}{ Variáveis } & \multicolumn{2}{|c|}{ Óleo essencial } & \multicolumn{2}{|c|}{ Cobre } \\
\hline & sem & com & sem & com \\
\hline AP & & & $11,13^{*}$ & 15,09 \\
\hline MSR & $1,45^{*}$ & 0,90 & $0,87^{*}$ & 1,48 \\
\hline MSA & & & $0,62 *$ & 0,96 \\
\hline MST & $2,25^{*}$ & 1,68 & $1,49 *$ & 2,44 \\
\hline $\mathrm{AP} / \mathrm{DC}$ & & & $2,46^{*}$ & 3,32 \\
\hline IQD & $0,63 *$ & 0,46 & $0,46^{*}$ & 0,63 \\
\hline $\mathrm{DC}$ & & & $3,10^{*}$ & 2,44 \\
\hline ASE & $35,77 *$ & 29,69 & & \\
\hline
\end{tabular}

* Teste F significativo a 5\% de probabilidade de erro dentro de cada fator de variação: óleo essencial ou cobre.

Fonte: Elaboração dos autores.

A análise da morfologia externa e interna do sistema radicular não evidenciou a formação de ectomicorriza nas duas espécies arbóreas estudadas em todas as combinações testadas. Estes resultados divergem do trabalho de Steffen et al. (2012), que trabalhando com sibipiruna (Caesalpinia peltophoroides Benth.) obteve a ocorrência de associação ectomicorrízica com a utilização de óleo essencial de eucalipto na dose de $40 \mathrm{uL} \mathrm{L} \mathrm{L}^{-1}$. A ausência de micorrização pode ser característica intrínseca às espécies nativas, como observado por Andreazza et al. (2008) em um trabalho com espécies arbóreas nativas com 17 anos de idade em ambiente natural no Estado do Rio Grande do Sul ou, pode ser induzida pela adubação fosfatada, pois segundo Diehl, Mazarrino e Fontenla (2008) baixas quantidades de fósforo tendem a favorecer a colonização micorrízica. É possível que as espécies estudadas não formem micorriza nas condições controladas de inoculação e de estímulo pelo óleo essencial.

A adição de cobre no solo com o objetivo de contaminar o ambiente com o metal contribuiu negativamente no crescimento das mudas de patade-vaca, com redução no diâmetro do colo e massa seca da parte aérea independente da adição ou não de inoculante e óleo (Tabela 4). O cobre, embora seja necessário para o crescimento e desenvolvimento de plantas (YRUELA, 2013), quando em excesso causa má formação das raízes, alterações na 
permeabilidade da membrana, clorose e redução da taxa fotossintética (KABATA-PENDIAS, 2010). Além de induzir a deficiência de ferro, quando em níveis tóxicos (MARSCHNER, 2011).

$\mathrm{Na}$ timbaúva-preta, a adição de cobre proporcionou maior qualidade de mudas e acréscimo na maioria dos parâmetros avaliados (Tabela 4). A tolerância ao cobre em espécies arbóreas nativas também foi observado por Silva et al. (2011b), na aroeira-vermelha (Schinus therebinthifolius Raddi) a qualidade das mudas não foi afetada até a dose de $256 \mathrm{mg} \mathrm{kg}^{-1}$ enquanto que no açoita-cavalo (Luehea divaricata Mart. \& Zucc.) não ultrapassou $64 \mathrm{mg} \mathrm{kg}^{-1}$. Diferentemente de mudas de canafístula (Peltophorum dubium) que apresentaram redução no comprimento e área superficial específica radicular com o aumento da quantidade de cobre no solo (SILVA et al., 2010). Isto significa que a adição da dose de $150 \mathrm{mg} \mathrm{kg}^{-1}$ de cobre no solo não atingiu o nível crítico de toxidez para interferir no crescimento e na qualidade das mudas, mostrando que a timbaúva-preta é mais tolerante do que a patade-vaca.

O índice de qualidade de Dickson utiliza atributos morfológicos que medem a robustez e o equilíbrio da distribuição da biomassa das mudas. Um bom indicador da qualidade de mudas é o valor mínimo de 0,2, preconizado por Dickson, Leaf e Hosner (1960) e Fonseca et al. (2002). Com base neste parâmetro, as mudas de timbaúvapreta apresentaram valores acima do ideal em todos os tratamentos, enquanto a pata-de-vaca apresentou valores abaixo do preconizado em todos os tratamentos (Tabela 2). Como o IQD mede a qualidade da muda, pode-se inferir que as mudas de timbaúva-preta apresentaram maior qualidade que as de pata-de-vaca.

Os resultados obtidos permitem inferir que as raízes das mudas de timbaúva-preta e pata-de-vaca não formam ectomicorriza com adição de inoculante líquido contendo fungo ectomicorrizíco. A adição de óleo essencial de eucalipto não proporciona estímulo à micorrização nas mudas de timbaúvapreta e pata-de-vaca. O crescimento das mudas da timbaúva-preta é estimulado pela adição de $150 \mathrm{mg}$ $\mathrm{kg}^{-1}$ de cobre em solo com $79 \%$ de argila e apresenta maior índice de qualidade de mudas em relação a pata-de-vaca.

\section{Agradecimentos}

A CAPES pela concessão da bolsa de Mestrado. Ao CNPq pelo auxílio financeiro por meio da bolsa PIBIC e à FAPERGS pela concessão da bolsa PROBIC.

\section{Referências}

ACCIOLY, A. M. A.; SIQUEIRA, J. O. Contaminação química e biorremediação do solo. In: NOVAIS, R. F.; ALVAREZ, V. V. H.; SCHAEFFER, C. E. (Org.). Tópicos em ciência do solo. Viçosa: Sociedade Brasileira de Ciência do Solo, v. 1, 2000. p. 299-352.

AKIYAMA, K.; MATSUZAKI, K.; HAYASHI, H. Plant sesquiterpenes induce hyphal branching in arbuscular mycorrhizal fungi. Nature, London, v. 435 , n. 7, p. 824$827,2005$.

ANDRADE, M. G.; MELO, V. F.; GABARDO, J.; SOUZA, L. C. P.; REISSMANN, C. B. Metais pesados em solos de área de mineração e metalurgia de chumbo. II - Formas e disponibilidade para plantas. Revista Brasileira de Ciência do Solo, Viçosa, MG, v. 33, n. 6, p. 1889-1897, 2009.

ANDREAZZA, R.; ANTONIOLLI, Z. I.; OLIVEIRA, V. L.; LEAL, L. T.; MORO, C. A. J.; PIENIZ, S. Ocorrência de associação micorrízica em seis essências florestais nativas do estado do rio grande do sul. Ciência Florestal, Santa Maria, v. 18, n. 3, p. 339-346, 2008.

BATISH, D. R.; SINGH, H. P.; KOHLI, R. K.; KAUR, S. Eucalyptus essential oil as nature pesticide. Forest Ecology and Management, Melbourne, v. 256, n. 12, p. 2166-2174, 2008.

BERTOLAZI, A. A.; CANTON, G. C.; AZEVEDO, I. G.; RAMOS, A. C. O papel das ectomicorrizas na biorremediação dos metais pesados no solo. Natureza on line, Santa Teresa, v. 8, n. 1, p. 24-31. 2010.

BONALDO, S. M.; SCHWAN-ESTRADA, K. R. F.; STANGARLIN, J. R.; CRUZ, M. E. S.; FIORI-TUTIDA, A. C. G. Contribuição ao estudo das atividades antifúngica 
e elicitora de fitoalexinas em sorgo e soja por eucalipto (Eucalyptus citriodora). Summa Phytopathologica, Botucatu, v. 33, n. 4, p. 383-387, 2007.

BRUNDRETT, M.; BOUGHER, N.; DELL, B.; GROVE, T.; MALAJCZUK, N. Working with mycorrhizas in foresty and agriculture. Canberra: ACIAR, 1996. 374 p.

CAMARGO, F. A. O.; BENTO, F. M.; JACCQUES, R. J. S.; ROESCH, L. F. W.; FRANKENBERGER, W. T. Uso de microrganismos para a remediação de metais. Tópicos Especiais em Ciência do Solo, Viçosa, v. 5, n. 1, p. 467496, 2007.

DIAGNE, N.; THIOULOUSE, J.; SANGUIN, H.; PRIN, Y.; KRASOVA-WADE, T.; SYLLA, S.; GALIANA, A.; BAUDOIN, E.; NEYRA, M.; SVISTOONOFF, S.; LEBRUN, M.; DUPONNOIS, R. Ectomycorrhizal diversity enhances growth and nitrogen fixation of Acacia mangium seedlings. Soil Biology and Biochemistry, Oxford, v. 57, n. 2, p. 468-476, 2013.

DICKSON, A.; LEAF, A. L.; HOSNER, J. F. Quality appraisal of white spruce and white pine seedling stock in nurseries. Forest Chronicle, Ontário, v. 36, n. 1, p. 1013, dez. 1960.

DIEHL, P.; MAZZARINO, M. J.; FONTENLA, S. Plant limiting nutrients in Andean-Patagonian woody species: effects of interannual rainfall variation, soil fertility and mycorrhizal infection. Forest Ecology and Management, Melbourne, v. 255, n. 7, p. 2973-2980, 2008.

DUARTE, N. F.; BUCEK, E. U.; KARAM, D.; SÁ, N.; SCOTTI, M. R. M. Mixed field plantation of native and exotic species in semi-arid Brazil. Australian Journal of Botany, Melbourne, v. 54, n. 8, p. 755-764, 2006.

DUARTE, N. F.; KARAM, D.; BUCEK, E. U.; MUZZI, M. R. S. Tolerance of Anadenanthera peregrina to Eucalyptus camaldulensis and Eucalyptus grandis essential oil as condition for mixed plantation. Brazilian Archives of Biology and Technology, Curitiba, v. 55, n. 3, p. 417-424, 2012.

EMPRESA BRASILEIRA DE PESQUISA AGROPECUÁRIA - EMBRAPA. Centro nacional de pesquisa de Solos (Rio de Janeiro). Sistema brasileiro de classificação de solos. Rio de Janeiro: Embrapa-SPI, 2006. 412 p.

FABROWSKI, F. J.; MUÑIZ, G. I. B.; NAKASHIMA, T.; NISGOSKI, S.; KLOCK, U. Investigação da presença de óleo essencial em Eucalyptus smithii R. T. Baker por meio da anatomia de seu lenho e casca. Ciência Florestal, Santa Maria, v. 13, n. 1, p. 95-106. 2003.

FERREIRA, D. F. Sisvar: a computer statistical analysis system. Ciência e Agrotecnologia, Lavras, v. 35, n. 6, p. 1039-1042, 2011.
FONSECA, É. P.; VALÉRI, S. V.; MIGLIORANZA, É.; FONSECA, N. A. N.; COUTO, L. Padrão de qualidade de mudas de Trema micrantha (L. ) Blume, produzidas sob diferentes períodos de sombreamento. Revista Árvore, Viçosa, v. 26, n. 4, p. 515-523, 2002.

GADD, G. M. Interactions of fungi with toxic metals. New Phytologist, Lancaster, v. 124, n. 1, p. 25-60, 1993.

KABATA-PENDIAS, A. Trace elements in soils and plants. 4. ed. Boca Raton, FL: CRC Press/Taylor \& Francis Group, 2010. 548 p.

LORENZI, H. Árvores brasileiras: manual de identificação e cultivo de plantas arbóreas do Brasil. 5. ed. Nova Odessa: Instituto Plantarum, 2008. v. 2. 384 p.

MARQUES, M.; AGUIAR, C. R. C.; SILVA, J. J. L. S. Desafios técnicos e barreiras sociais, econômicas e regulatórias na fitorremediação de solos contaminados. Revista Brasileira Ciência Solo, Viçosa, MG, v. 35, n. 1, p. 1-11, 2011.

MARSCHNER, P. Marschner's mineral nutrition of higher plants. Amsterdam: Elsevier/Academic Press, $2011.684 \mathrm{p}$.

MARX, D. H. The influence of ectotrophic mycorrhizal fungi on the resistance of pine roots to pathogenic fungi and soil bacteria. I. Antagonism of mycorrhizal fungi to root pathogenic fungi and soil bacteria. Phytopathology, St. Paul, v. 59, n. 2, p. 153-163, 1969.

NACHTIGALL, G. R.; NOGUEIROL, R. C.; ALLEONI, L. R. F.; CAMBRI, M. A. Copper concentration of vineyard soils as a function of $\mathrm{pH}$ variation and addition of poultry litter. Brazilian Archives of Biology and Technology, Curitiba, v. 50, n. 6, p. 941-948, 2007.

OLIVEIRA, V. L.; OLIVEIRA, L. P.; ROSSI, M. J. Ectomicorrizas no Brasil: diversidade de fungos e aplicação. In: SIQUEIRA, J. O.; SOUZA, F. A.; CARDOSO, E. J. B. N.; TSAI, S. M. (Org.). 30 anos de pesquisas sobre micorrizas no Brasil. Lavras: Editora UFLA, 2010. p. 645-677.

SERAFINI, L. A.; CASSEL, E. Produção de óleos essenciais: uma alternativa para a agroindústria nacional. In: SERAFINI, L. A.; BARROS, N. M.; AZEVEDO, J. L. Biotecnologia na agricultura e na agroindústria. Guaíba: Agroindústria, 2001. 463 p.

SILVA, R. F.; ANTONIOLLI, Z. I.; LEAL, L. T.; LUPATINI, M.; SALLES, A. S. Tolerância de mudas de canafístula Peltophorium dubium (SPRENG.) Taub. inoculada com Pisolithus microcarpus a solo com excesso de cobre. Ciência Florestal, Santa Maria, v. 20, n. 1, p. 1-6, 2010. 
SILVA, R. F.; ANTONIOLLI, Z. I.; LUPATINI, M.; LEAL, L. T. Ectomicorrização em quatro espécies florestais nativas do Rio Grande do Sul e sua eficiência em solo contaminado por cobre. Ciência e Natura, Santa Maria, v. 33, n. 2, p. 95-109, 2011 b.

SILVA, R. F.; SAIDELlES, F. L. F.; SILVA, A. S.; BOLZAN, J. S. Influência da contaminação do solo por cobre no crescimento e qualidade de mudas de açoitacavalo (Luehea divaricata Mart. \& Zucc.) e aroiravermelha (Schinus therebinthifolius Raddi). Ciência Florestal, Santa Maria, v. 21, n. 1, p. 111-118, 2011 a.

SMITH, S. E.; READ, D. J. Mycorrhizal symbiosis. 3. ed. New York: Academic Press, 2008. 800 p.

SOUZA, E. L.; ANTONIOLLI, Z. I.; MACHADO, R. G.; ECKARDHT, D. P.; DAHMER, S. F. B.; SCHIRMER, G. K. Efeito da inoculação com isolados de fungos ectomicorrízicos sobre o desenvolvimento de mudas de Eucalyptus grandis Hill ex Maiden. Ciência Florestal, Santa Maria, v. 22, n. 2, p. 251-261, 2012.

STEFFEN, R. B.; ANTONIOLLI, Z. I.; STEFFEN, G. P. K. Efeito estimulante do óleo essencial de eucalipto na germinação e crescimento inicial de mudas de Eucalyptus grandis. Pesquisa Florestal Brasileira, Colombo, v. 30, n. 63 , p. 219-225, 2010.

STEFFEN, R. B.; ANTONIOLLI, Z. I.; STEFFEN, G. P. K.; JACQUES, R. J. S.; ECHKARDT, D. P.; SANTOS, M. L.; SANTANA, N. A. Efeito do óleo essencial de Eucalyptus grandis no crescimento de isolados de fungos ectomicorrízicos em diferentes concentrações de cobre, zinco e níquel. Pesquisa Florestal Brasileira, Colombo, v. 31, n. 67, p. 227-234, 2011.
STEFFEN, R. B.; ANTONIOLLI, Z. I.; STEFFEN, G. P. K.; SILVA, R. F. Óleo essencial de Eucalyptus grandis Hill ex Maiden no estimulo à micorrização de mudas de sibipiruna (Caesalpinia peltophoroides Benth). Ciência Florestal, Santa Maria, v. 22, n. 1, p. 69-78, 2012.

TENNANT, D. A test of a modified liwe intersect method of estimating root lengh. Journal Ecology, Wisconsin, v. 63, n. 3, p. 995-1001, nov. 1975.

VERDEGUER, M.; BLÁZQUEZ, M. A.; BOIRA, H. Phytotoxic effects of Lantana camara, Eucalyptus camaldulensis and Eriocephalus africanus essential oils in weeds of Mediterranean summer crops. Biochemical Systematics and Ecology, Kew, v. 37, n. 4, p. 362-369, 2009.

VITTI, A. M. S.; BRITO, J. O. Óleo essencial de eucalipto. São Paulo: Universidade de São Paulo, Escola superior de Agricultura Luiz de Queiroz, 2003. 26 p. (Documentos, 17).

YRUELA, I. Transition metals in plant photosynthesis. Metallomics, London, v. 5, n. 9, p. 1090-1109, 2013.

ZHANG, C.; FU, S. Allelopathic effects of eucalyptus and the establishment of mixed stands of eucalyptus and native species. Forest Ecology and Management, Melbourne, v. 258, n. 7, p. 1391-1396, 15 set. 2009. 